\title{
THE ACTION OF ORGANIC AND MINERAL ACIDS UPON SOILS.
}

\author{
HY HARISY STYHRK
}

$I^{\prime}$

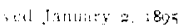

I soil analysis, the hychochloric acid use for dissolving the potash, lime. and phosphates has a specific gravity of I.1 15 . This acid is used because it is supposed to represent, practically, the same solvent power which agricultural plants possess in obtaining their food from the soil. Inasmuch as this premises is the foundation of a part of the present system of soil analysis, it is a question of the greatest importance. One of the indications which points to the truth of the premises is the similarity of the action of hydrochloric acid of this strength, and of organic acids upon samples of soil.

()rganic Acids. - In some of the soil work which has been in prouress in the chemical laboratory of the Minnesota Experiment Station, the solvent action of the various organic acids has been determined with another ultimate object in view. Incidentally, the resulti give sufficient data for the comparative action of the organic acidis and of hyclrochloric acid, sp.gr., I. I I5, upon the same samples of soil.

Different types of soil are acted upon quite differently by the various organic acicls, and general conclusions regarding their action upon various types of soil can not be stated. Hence the statements which are made upon this question have reference only to the type of soil under consideration.

The figures given in the table were obtained from a soil sample taken from one of the rotation plots at the Experiment Station. In obtaining the solutions for analysis, oxalic, tartaric, and citric acids, of ten per cent. strength, by weight, were used. The digestion was carried on for thirty-six hours in the Snyder soil flask as used at this station. The organic acid mixture was made by preparing a ten per cent. solution, by weight of citric, oxalic, and tartaric acids. The material soluble in the organic acids was separated by filtration and washing. The solution was then gently ignited to remove the organic acids, so that the analysis could be completed in the usual way. 
Ten per cent. solutions were used because the more concentrated ones crystallized upon standing, and, then too, preliminary trials indicated that the more concentrated organic acid solutions possessed less solvent power than those here used. One difficulty experienced in the work was obtaining tartaric acid free from potash, and citric and oxalic acids free from lime. All of the determinations were made in duplicate, and controlled by blank determinations.

\section{TABLE I.}

Solvent ACtion of Hydrochloric and Organic Acids upon a Soll.

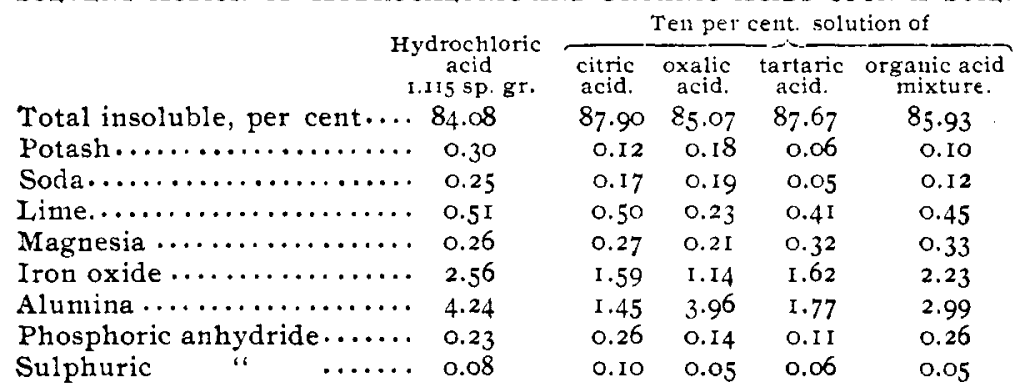

The oxalic acid caused an increase in the solubility of the alumina. There is a marked difference between the solvent action of these three acids. The oxalic acid possesses the greatest solvent action upon the complex insoluble matter of an alkaline nature. The citric acid possesses the greatest solvent action upon the lime, magnesia, and the sulphuric and phosphoric anhydrides. The amount of lime dissolved by the oxalic acid is greater than would, at first, be expected, but the complex nature of the solution, and the presence of the salts of other metals, has caused nearly half as much lime to be dissolved by the oxalic acid as by the hydrochloric acid of sp. gr. I.II 5 .

The ten per cent. mixture of the three organic acids has resulted in dissolving as much phosphates and magnesia, and nearly as much lime as any one of the acids acting alone. The potash does not appear to be as soluble in the organic acid mixture as the other elements of plant food.

The amount of potassium, iron, and aluminum oxides, dissolved by these three organic acids and their mixtures is somewhat less than that dissolved by the hydrochloric acid. The 
iron and alumina are not of any economic importance in interpreting the results of soil analysis. The main difference between the solvent action of the hydrochloric and the organic acids is in the somewhat smaller amount of potash dissolved by the organic acids.

With the exception of the solubility of the potash, as noted, these results bring out, in a general manner, the value of hydrochloric acid of I. I $5 \mathrm{sp}$. gr. as a solvent, over the organic acids, of ten per cent. strength, because the hydrochloric acid represents the limit of the solvent action reached by any one of the organic acids acting alone or in a mixture.

For the purpose of comparison, the solvent action of hydrochloric acid, sp.gr. I.I 5 , and the maximum limit reached in any case, by the organic acids, are given, together with the name of the acid possessing the highest solvent power for that constituent.

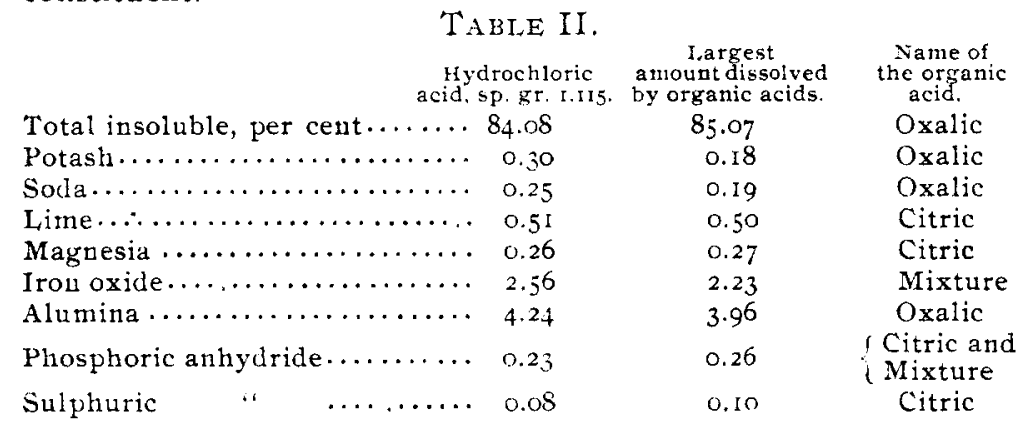

Minciat Acids. -.. The action of the concentrated mineral acids upon the same sample of soil is given in Table III. Concentrated hydrochloric acid, forty per cent. strength, dissolved two and a quarter per cent. more of the complex silicates than nitric acid of the same strength. Concentrated nitric acid possesses a stronger solvent action than the dilute hydrochloric acid. The concentrated hydrochloric acid dissolved somewhat more potash than the hydrochloric acid of I.II5 sp. gr. The amount of line, phosphates, and sulphates, dissolved by the concentrated hydrochloric acid, was about the same as when the more dilute acid was used; the concentrated acid, however, dissolved more of the complex silicates of potash, iron, and alumina. Sulphuric acid possesses the strongest solvent action. 
Of the total potash in the soil, as determined by fusion, less than eighteen per cent. is soluble in the hydrochloric acid as used in soil analysis; about ten per cent. is soluble in oxalic acid, and three per cent. in tartaric acid.

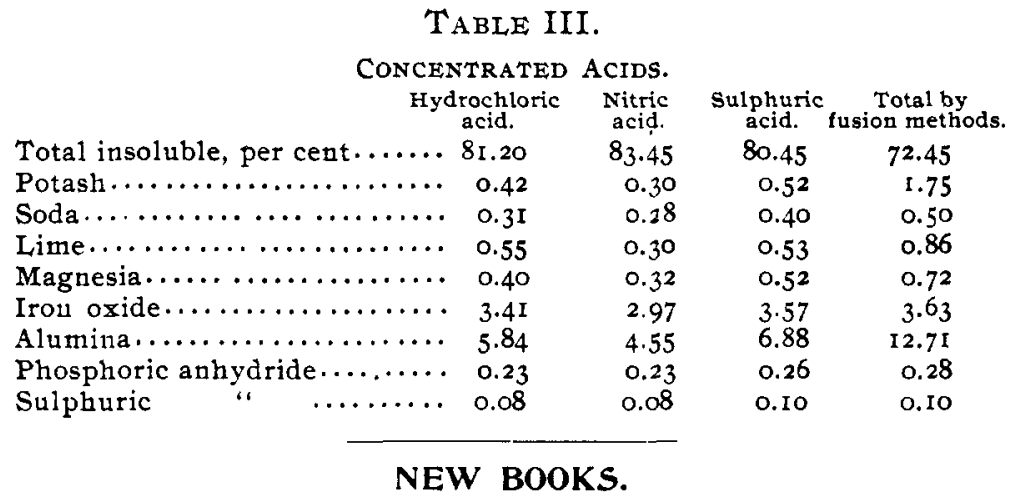

A Treatise on Industrial Photometry, with Special application to Electric Lighting. By A. Palaz, Professor of Industrial, Electricity IN THE ScIENCE Faculty OF THE UNIVERSiTy OF LAUsanne. Translation by Geo. W. Patterson, Jr., Assistant ProFESSOR OF PhySics IN THE UNIVERSITy OF Michigan, aNd M. R. Patterson, pp. 322. New York: D. Van Nostrand Co., 1894. Price, $\$ 4.00$.

Many of the methods of photometry which have been long in use for measuring the intensity of light from gas flames have required modification when applied to the measurement of the intense light produced by electricity. A book which gathers together and arranges, systematically, the work on the subject which is scattered in many different journals, and which is frequently difficult of access, will be very welcome to many who are interested in the subject.

The first part of the book gives a discussion of the general principles of photometry and includes a description of all of the common photometers and photometric standards. This part of the book is quite full and will be of value to anyone interested in photometry in any of its applications. Then follow chapters on the equipment of photometric laboratories, and on the measurement of the intensity and distribution of light from electrical sources. 